\title{
El proyecto Datos Abiertos del Patrimonio Cultural Andaluz
}

José Luis Zafra Ojuel, David Villalón Torres | Área de Sistemas de Información, Dirección Económica y Financiera, Instituto Andaluz del Patrimonio Histórico

URL de la contribución <www.iaph.es/revistaph/index.php/revistaph/article/view/3966>

En la actualidad estamos asistiendo al surgimiento de una nueva realidad social y económica basada en la gestión y acceso al conocimiento. Es lo que se denomina economía del conocimiento. Este nuevo fenómeno está afectando de manera profunda a las organizaciones públicas fundamentalmente por dos razones: son los principales generadores de la información de uso público; y-debido a su carácter prestacional y de servicio- tienen la obligación de adaptarse a las nuevas demandas impuestas por la sociedad y la tecnología en este contexto de interoperatividad y reutilización de la información. Estas demandas se pueden resumir en el impulso de dos estrategias básicas: cooperar con otras organizaciones y compartir conocimiento. Estrategias que han sido recogidas y trasladadas al plano normativo desde las administraciones públicas bajo el paraguas del open data.

Las iniciativas de open data se impulsan desde Europa en un primer momento, con la Directiva Europea 2003/98/ CE y se trasponen a nivel nacional creando un marco normativo adecuado con la Ley 37/2007 y la Ley 18/2015. Esta legislación regula la reutilización de la información pública y establece la creación de catálogos de datos públicos comunes y federados. En España se crea el Catálogo Nacional de Datos Abiertos (datos.gob.es) y se establece la obligatoriedad de publicar información sobre los contenidos disponibles para su reutilización. Por su parte, la Junta de Andalucía viene desarrollando un proyecto liderado por la Consejería de la Presidencia y Administración Local en el que se impulsa un catálogo de datos abiertos proporcionados por distintas entidades de la Junta de Andalucía. Esta iniciativa tiene también como objetivos la creación de un lenguaje común para el modelado de la información de los distintos datos a publicar. De esta manera se facilita la interoperabilidad de los datos proporcionados en el catálogo.
Todo este esfuerzo se enfoca en potenciar la reutilización de la información pública. Porque se parte de la premisa de que "innovar es encontrar nuevos o mejorados usos a los recursos que disponemos" (Peter Drucker) y se entiende que el conocimiento es el activo principal en las organizaciones públicas (MENCHERO, 2016). Ya que la información generada por la Administración tiene unas características que la hacen especialmente útil para la ciudadanía: es de calidad, fiable y completa.

Estas iniciativas y este nuevo enfoque están impulsando la modernización del sector público, articulándolo a través de un nuevo esquema de relaciones con la ciudadanía y las empresas, donde los objetivos son la eficiencia y la contribución para generar riqueza.

Podemos decir, por tanto, que la reutilización de información es una obligación que tienen los poderes públicos que potencia la innovación y la transparencia administrativa ligada a los principios democráticos de participación y colaboración; al tiempo que puede contribuir a la promoción de acciones que favorezcan el crecimiento económico.

En este contexto, se entiende que la información tiene valor y capacidad para fomentar la innovación. Pero no toda la información es igual de atractiva para los diferentes actores potenciales que participan en su reutilización (denominado también sector infomediario) (CARACTERIZACIÓN, 2016). En este sentido, la información sobre el patrimonio cultural tiene una importante demanda y una gran versatilidad para favorecer su reutilización por parte de las industrias creativas y culturales en diferentes ámbitos. Ya sea como elemento para ayudar a construir una sociedad cohesionada -sobre la base de una identidad común pero diversa al mismo tiempo- o como un recurso fundamental para el desa- 


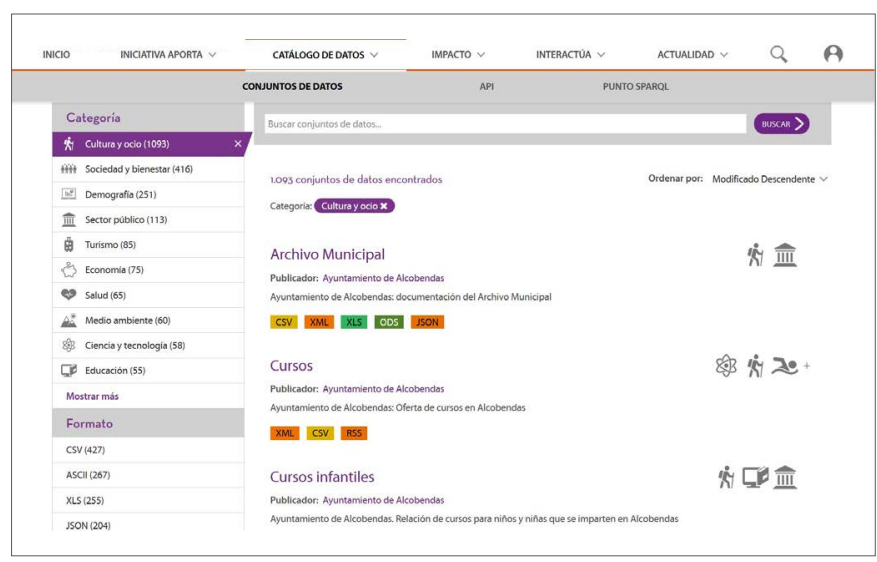

Categoría cultura y ocio en el Catálogo Nacional de Datos Abiertos (http://datos gob.es/es/catalogo?theme_id=cultura-ocio)

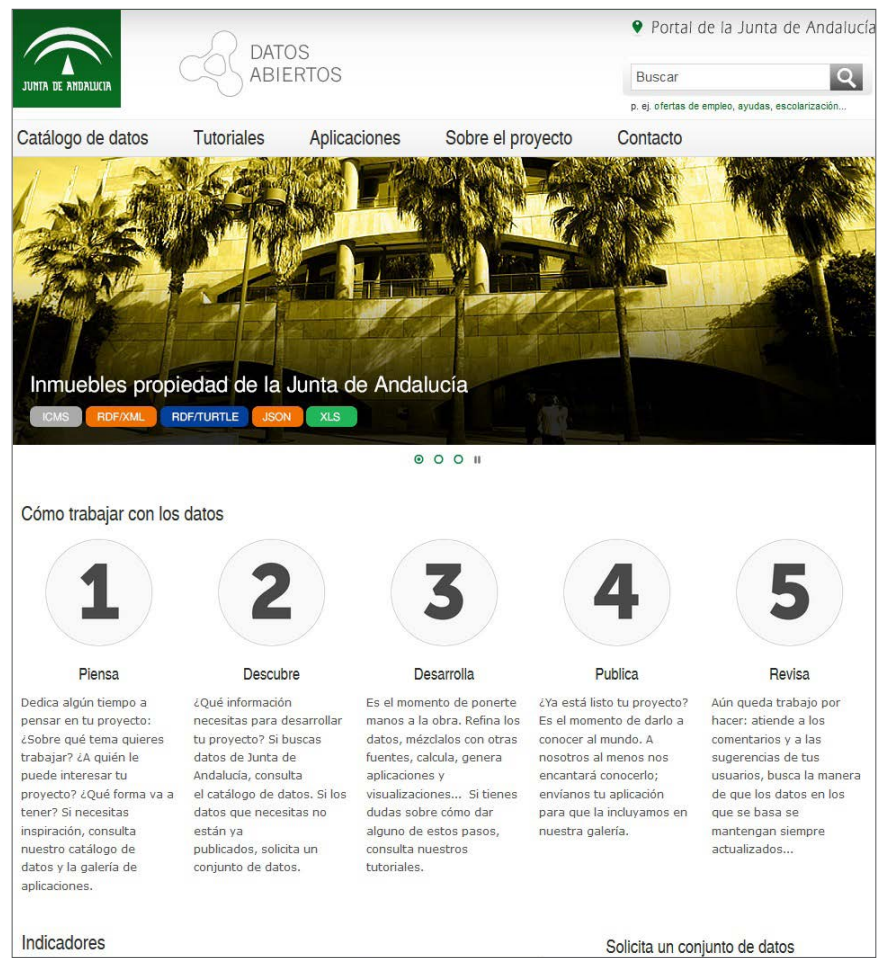

Portal de datos abiertos de la Junta de Andalucía (http://juntadeandalucia.es/ datosabiertos/portal.html)

rrollo económico basado en nuevos modelos de negocio para las industrias creativas y culturales (ESTUDIO, 2014). De hecho, la principal virtud de los datos abiertos es que el uso y aplicaciones de los datos no está prede- finido. Al poner los datos abiertos a disposición de miles de personas, con distintas necesidades, habilidades y motivaciones, pueden concebirse nuevas utilidades para los datos, ya sea por sí mismos, como interrelacionándolos con otros conjuntos de datos abiertos.

En Andalucía, el Instituto Andaluz del Patrimonio Histórico (IAPH) es la entidad científica de la Consejería de Cultura de la Junta de Andalucía dedicada al patrimonio cultural desde 1989. Una agencia pública que se configura como un centro de excelencia que integra todas las disciplinas del patrimonio cultural: investigación del patrimonio, documentación, conservación de bienes culturales, restauración del patrimonio histórico, difusión y formación, entre otras.

Su registro oficial como agente del Sistema Andaluz del Conocimiento, en la clasificación concreta de instituto de investigación, reconoce el papel fundamental del IAPH en la producción científica y su labor de transferencia hacia el tejido productivo andaluz y la sociedad en su conjunto.

EI IAPH tiene una dilatada experiencia en generación, sistematización y distribución de información y conocimiento del patrimonio cultural andaluz. Todo el activo informacional generado a lo largo de su historia constituye un potente motor de riqueza que puede contribuir a impulsar en Andalucía la economía del conocimiento a través de la creación de productos y servicios con valor añadido.

El activo informacional del IAPH publicado se representa en las siguientes cifras a día de hoy:

$>26.024$ registros sobre bienes inmuebles.

$>84.823$ registros sobre bienes muebles.

$>48.772$ referencias bibliográficas.

> 73.824 documentos gráficos, básicamente fotografías, pero también imágenes $360^{\circ}$ y videos inmersivos.

$>$ Información de interés de otras webs: 1.220 recursos.

$>32$ demarcaciones paisajísticas.

$>21$ rutas culturales.

$>5.887$ bienes patrimoniales georreferenciados. 


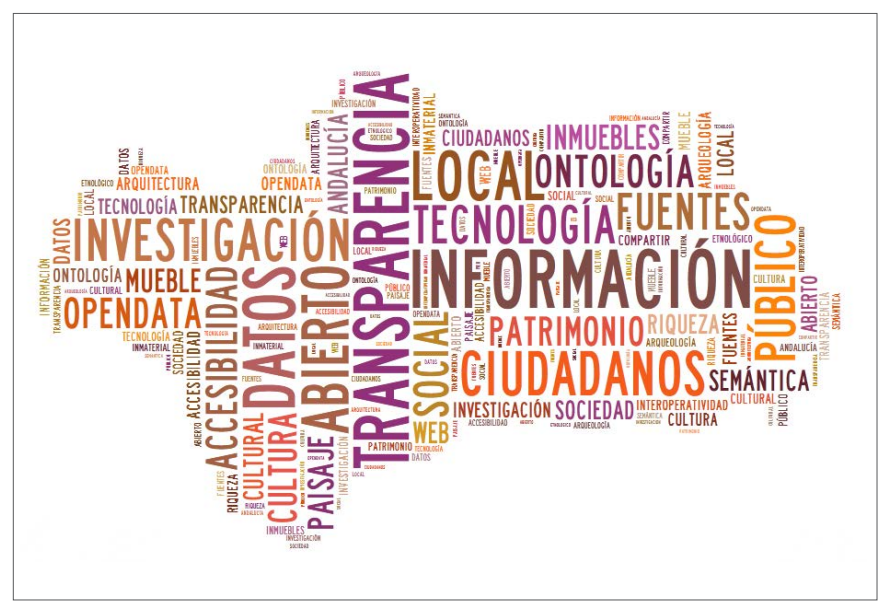

Proyecto Datos Abiertos del Patrimonio Cultural de Andalucía

$>1.255$ fichas de actividades vinculadas con el patrimonio inmaterial.

Entendemos que el compromiso de una institución pública cultural dedicada a la investigación tiene que estar directamente relacionado con la transferencia de la información, que es su activo más preciado y su razón de ser; ya sea hacia la ciudadanía en general, la comunidad científica/investigadora o al sector infomediario. Con este espíritu presentamos en 2012 el proyecto Datos Abiertos del Patrimonio Cultural de Andalucía. Dicho proyecto consiste en el desarrollo, implantación y distribución de un sistema de conocimiento abierto y estructurado del patrimonio cultural andaluz, basado en linked open data y el modelo de datos CIDOC-CRM: una ontología que agrupa los diferentes ámbitos de conocimiento del patrimonio cultural y que proporciona un esquema de datos común y reutilizable. El proyecto fue aprobado provisionalmente en 2014, pero hasta 2017 no se procedió a su aprobación definitiva. Actualmente está en desarrollo y verá la luz en 2018.

Este proyecto permitirá que el conocimiento generado por el IAPH en sus 20 años de historia pueda ser reutilizado por la ciudadanía, favoreciendo la transferencia de conocimiento, generando riqueza y potenciando nuevos nichos de mercado en la sociedad andaluza.

\section{BIBLIOGRAFÍA}

- CARACTERIZACIÓN del sector infomediario en España. Edición 2016. Observatorio Nacional de las Telecomunicaciones y de la Sociedad de la Información (ONTSI) <http://datos.gob.es/sites/default/files/doc/file/estudio de caracterizacion del sector_infomediario_2016_0.pdf> [Consulta: 19/07/2017]

- ESTUDIO del gasto cuttural de Europa y de los estados miembros durante la crisis 2007-2014. Fondo Europeo de Equidad Cultural. Fundació Catalunya Europa, 2016. <http:// www.catalunyaeuropa.net/img/pdf/Policy_Paper_Culture_ Spending_Nov_16_1_2.pdf> [Consulta: 20/07/2017]

- MENCHERO DE LOS Ríos, C. (2016) La filosofía open data en el ámbito cultural: innovación y nuevos modelos de negocio. Blogthinkbig.com, 2016 <http://aunclicdelastic.blogthinkbig. com/la-filosofia-open-data-en-el-ambito-cultural-innovacion-ynuevos-modelos-de-negocio/> [Consulta: 19/07/2017] 